\title{
A Case Study Examining How the Use of a Module-Specific Hashtag Can Enhance Student Engagement among Journalism Undergraduates
}

\section{Tom Bradshaw, University of Gloucestershire, USA}

\begin{abstract}
The incorporation of smartphones and social media into teaching is entering the mainstream in Higher Education institutions as interactive e-learning becomes a key strand of universities' pedagogical strategies. The use of such technologies is particularly relevant for journalism students, given the social media-driven context in which much contemporary journalism is produced. The purpose of the study was to explore whether social media could be used to encourage both in-class and out-of-class module engagement among first-year Journalism undergraduates at the University of Gloucestershire. The study focused on the use of a module-specific hashtag on Twitter throughout a single-semester journalism studies module, and the extent to which students used the hashtag in their own tweets. At the beginning of the study, a questionnaire was used to collect data about students' news consumption habits and their preferred social media platforms for news. The findings show that the majority of participants use their mobile phone as the primary means of accessing news, with Twitter the most frequently used social media platform. Quantitative research on students' use of the hashtag was then gathered by monitoring Twitter, with tweets subjected to content analysis. The study showed that the use of the module hashtag produced significant levels of both inclass and out-of-class student engagement, with engagement continuing after teaching on the module had ended. The findings are supplemented by autoethnographic reflections by the module tutor. The findings of the study provide insight into how social media-based teaching techniques could be used to enhance engagement among media students. In the course of the study, the pedagogical positions of augmented reality teaching and pedagogy-industry alignment are delineated and explored.
\end{abstract}




\section{Introduction}

The potential of digital technology, particularly the so-called social web, to enhance Higher Education teaching has been a central feature of pedagogical debate in the UK ever since universities recognised that a shift in young people's "online lifestyle" necessitated a change in teaching strategy (Melville 2009). The capacity for new technologies to deliver improved learning outcomes has subsequently been highlighted in a number of studies (Junco, Elavsky \& Heiberger 2013; Junco, Heiberger \& Loken 2011). The emergence of e-learning strategies and technology-infused teaching has given rise to a debate about whether Higher Education institutions (HEIs) are undergoing a "reinvention of the campus" (Cochrane 2014), with the consequent demise of traditional teaching methods (Dawson 2014). While reports of the death of the traditional university may have turned out to be exaggerated, there is a general acceptance that digital technology - particularly the use of social media - has engendered what Williams, Brown and Benson call a more "egalitarian nature of interaction" between lecturer and student (2013: 120). While Williams, Brown and Benson's focus is on how such technology affects feedback - extending "the boundaries of how both synchronous (real-time) and asynchronous (delayed-time) feedback can be implemented and provided" (ibid.) - their point can be broadened to apply to teaching more generally, with the social web facilitating both the sharing of, and the interaction with, course-related material. This study seeks to apply this insight to a specific module at a UK university, and focuses on how the semesterlong use of a module-specific hashtag on the social media platform Twitter served to enhance journalism students' engagement with the module. The use of Twitter is particularly relevant for journalism students, given the social media-driven context in which much contemporary journalism is produced, distributed and consumed.

It is important to state at the outset that this study was prompted by the author's own interest in how technology can be utilized to enhance student experience, and as such the study has an autoethnographic strand in which my own experiences, and my in-depth reflections on those experiences, are a significant element. As well as being informed by an autoethnographic paradigm, this study operates from a number of conceptual premises which have been influenced by my teaching experiences 'in the field'. Firstly, it is assumed that Higher Education should regard itself as operating as a part of what has been called the attention economy, in which attention - defined as visitors/viewers to a piece of content - in a mediasaturated world is a scarce and valuable commodity which everyone from businesses to 
celebrities aspire to obtain (Chayko, 2017; Ingram 2015; Marwick 2015). If attention is the most valuable currency in the contemporary media world, then HE teaching, particularly of media subjects, should seek to trade in that currency and compete with the other media content trying to attract eyeballs. Secondly, the study is underpinned by Jurgenson's rejection of 'digital dualism' (2012). Digital dualism is the binary distinction between the offline and online, which regards the two spheres as being entirely distinct and experienced separately. Applying Jurgenson's concept to teaching, this study contends that it is bogus and unhelpful to think of offline and online teaching spaces as clearly separate. Current undergraduate students, with the exception of some mature students, are what Williams, Brown \& Benson (2013) refer to as 'Generation Z' or 'the net generation'. Digital natives, they have never known life without the web. They are highly connected through the social web and have a lifelong familiarity with digital applications, a familiarity which means their offline and online worlds continually collide. A contention of this paper is that future elearning strategies should reject crude distinctions between online and offline teaching, and embrace the ongoing - and inevitable - collisions of digital and non-digital spaces.

\section{Augmented Reality Teaching and Pedagogy-Industry Alignment}

The emergence of a pervasive digital culture and the manner in which this has affected interactions between people has led to some media theorists arguing that the way in which reality is experienced has been fundamentally altered (Chayko 2017; Jurgenson 2012). The online and the offline are now elaborately interwoven, or, as both Chayko and Jurgenson phrase it, "enmeshed":

Individuals often have experiences that are not neatly categorized as digital or face-toface, as online or offline. They may use digital technology in combination with more traditional means of interaction in forming and maintaining relationships. Binary categories have serious limitations as we attempt to understand modes of interaction that overlap and intersect one another... the online and offline are generally experienced in combination with one another. They are enmeshed. People are often so deeply, so comprehensively affected by the infusion of technology into their everyday lives that a highly useful way to think about these lives - these spaces and experiences and relationships and communities and societies - is that they are techno-social." (Chayko, 2017: 4-5) 
Jurgenson (2012) describes the tendency to regard the online and offline as distinct spaces as "digital dualism", a binary concept which he regards as spurious. He contends that "the new technologies in question - especially the highly interrelated mobile web and social media effectively merge the digital and physical into an augmented reality", with 'augmented' defined by him as "a larger conceptual perspective that views our reality as the byproduct of the enmeshing of the on and offline" (Jurgenson 2012: 2). By 'augmented reality', Jurgenson is referring not to software applications but to a theoretical perspective which "holds that our reality is the blurring of the on and offline" (Jurgenson 2012: 3). As such, it is inaccurate to say of a particular experience that it must necessarily be either digital or offline; a blunt either/or dichotomy is misguided. "The online and offline are not separate spheres and are thus not zero-sum. Dialectically related, one can be used to bolster the other" (Jurgenson 2012: 3).

This dialectical process is arguably one which goes unrecognized by digital natives whose lives are conducted at the intersection between online and offline. This is a point articulated by Chayko, who follows Jurgenson in rejecting any notion of digital dualism. "Those who have grown up immersed in the internet and digital media use may see the online and offline as melding seamlessly. Youth may be ushering in an era in which distinctions between the online and offline, and the real and the unreal, are becoming deeply blurred, if not obliterated" (Chayko, 2017: 67).

The contention of this paper is that learning and teaching strategies should be similarly nonbinary, with an explicit rejection of any hard and fast distinction between e-learning methods on the one hand and standard (or 'traditional') teaching methods on the other. Adapting Jurgenson's concept of augmented reality, it contends that pedagogical strategies should be underpinned by an approach of augmented reality teaching, where the online and offline are not regarded as separate spheres for teaching but are instead regarded and used as co-existing, concurrent and overlapping realms. As well as making this general pedagogical claim, the paper also makes a more specific claim, namely, that for journalism students, it is important that the platform for educational delivery mirrors the platform(s) on which the students' subsequent professional work will take place. Given Twitter's ubiquitous use by professional journalists as a newsgathering, dissemination and promotional tool, it is vital for journalism courses to prepare students how to use Twitter, and indeed other social media platforms, with 
professional sophistication. Using Twitter to teach first-year journalism students - even for a theoretical module - thus immediately immerses them in a technology that they will be required to master. This harmonious alignment between the platform on which students are taught and the platform which they will be required to use in industry can be termed pedagogy-industry alignment.

\section{Hashtags, teaching and Twitter}

A hashtag is a means of enabling social media content to be grouped together and discovered. Using the hash (\#) symbol followed by a key phrase, the intention of a hashtag is to make social media content about a particular topic rapidly searchable and discoverable. Hashtags are used both by those posting a piece of content and by those searching social media to find content about a particular topic. A powerful example of a hashtag was the use of \#JeSuisCharlie following the massacre at the offices of the Charlie Hebdo magazine in Paris in 2015. The module which is the focus of this study was a first-year introduction to journalism studies called The Power of News, and on students' timetables the module had the code of MD4101. Consequently, the code MD4101 was made into the hashtag '\#MD4101'. Students on the module could post content to Twitter using the hashtag \#MD4101 knowing that both classmates and the tutor would also be using the hashtag and searching for content that featured the tag.

The application and development of hashtags as an educational tool is not an original idea. Jimerson (2015) describes how she used Twitter and a module hashtag in an effort to make an art history module at a university in the United States "more interactive and relatable to a $21^{\text {st }}$ century audience". In an effort to stimulate uptake in the use of the hashtag, Jimerson offered the incentive of two bonus assessment percentage points for those students who used Twitter as part of the module. Her study concluded that about $50 \%$ of students participated to a greater or lesser extent in the use of the hashtag, and emphasised how the option of using the hashtag brought some quieter students forward. "In a large lecture hall, it can be intimidating for some students to participate. Twitter allowed everyone in the class to express their ideas while simultaneously strengthening the classroom community" (ibid.). Elsewhere, the deliberately unstructured pedagogical approach of rhizomatic learning - which contends that "the community is the curriculum" - has encouraged people to use a hashtag to share their thoughts on a topic (Cormier 2014). Rhizomatic learning emphasises how sense-making and 
knowledge-acquisition is a collaborative practice, and from this starting point the use of a hashtag is regarded as a means by which multiple voices can contribute to a process of organic discovery, in something of an analogous way to a how a rhizome plant stem propagates organically by sending out roots into its surroundings.

Twitter was the first social media platform where the device of the hashtag was developed and established, and it is relevant for the purposes of this study to make it clear that the author had used Twitter as a significant teaching tool on other modules prior to the commencement of the current study. Previously, I had used Twitter to remotely deliver synchronous feedback to sports journalism students who were producing content from the press box of a live football match. My prior teaching and use of Twitter had also suggested to me how monitoring media students' social media output could be used to gauge whether or not a skill or concept had been properly grasped by the students. If, for example, a student's tweet suggested that a technique discussed in class had only been half-understood, then that would prompt me to return to that topic and address the misapprehension, a process referred to by Williams, Brown and Benson (2013) as "responsive adjustment". These experiences helped provide the impetus for the case study.

\section{Method}

The case study is of a compulsory first-year undergraduate journalism studies module called MD4101 The Power of News. The module consisted of 12 weeks of teaching, with each week comprising a two-hour lecture and a one-hour seminar. The number of students enrolled on the module (the sample) was 73, comprising 44 BA Sports Journalism students and 29 BA Journalism students. The author was the module tutor responsible for the design, teaching and marking of the module. The research aim of the case study was to gain insight into how the use of a module-specific hashtag, namely \#MD4101, could enhance journalism students' engagement with the course.

As outlined in the Introduction, the study has an autoethnographic current running through it and is underpinned by the interpretivist ontology and epistemology implicit in Jurgenson's theory of 'augmented reality', where reality is regarded as being constructed from the interweaving flow of digital and non-digital experiences. Autoenthnography is developing a growing role in education research (O'Reilly 2012) and can "help humanize emotionally 
sterile research projects" (Ellis and Adams, 2014: 255) by providing "rich and nuanced insights into personal lived experience and situating these within a wider socio-cultural context" (Allen-Collinson, 2012: 208). My own experiences as a university lecturer and my efforts to engage students using digital technology constitute both the backdrop and the impetus to this research, and my ongoing reflections on my teaching practice provide the humanization and nuance to the case study that Ellis and Adams, and Allen-Collinson, refer to respectively. Throughout the module I acted as a reflexive practitioner, monitoring the students' and my own use of Twitter and reflecting on how the hashtag could be incorporated into the delivery of module content without becoming over-used or dull.

The case study is also informed by quantitative and qualitative data. A questionnaire about students' media consumption habits was handed to all attending students at the start of the module. The purpose was to collect data about the students' preferred social media platforms for news content, and to also discover what media platforms more generally were most popular among the journalism students. The questionnaire was distributed at the end of the first lecture in September 2015 and students were asked to complete it in their own time and return it at the start of the following week's session. Forty-two questionnaires were returned, providing a completion rate of $57.5 \%$.

During the module, tweets from the tutor using the \#MD4101 hashtag were made from the @BASportsJourno Twitter handle - the course Twitter account for the BA Sports Journalism programme. The 'terms of use' for the use of the hashtag and Twitter during the module were verbally outlined to students in the first week of the class; these emphasized how students would find content from the tutor posted on Twitter both during class and outside of class time, and how they were encouraged to post their own thoughts and links to third-party content. In keeping with the principles of augmented reality teaching outlined in the Introduction, the use of smartphones and tablets was actively encouraged in class. Unlike Jimerson (2015), no bonus mark incentives were used to try and induce students to use Twitter as part of the module, as it was felt that this could be an artificial inducement that would skew the findings into the research question of how successful a Twitter module hashtag can be in improving student engagement. 
At the end of the module, tweets were categorized in three groups depending on who had posted them - students, module tutor and tutors not teaching on the module - and subjected to content analysis. This content analysis considered the different types of content (e.g. links to relevant online articles, in-class comment) which were posted using the module-specific hashtag. Triangulating this content analysis with the autoethnographic data enabled a rich picture of student engagement to emerge.

\section{Results}

\section{Overview}

The findings show that journalism students arriving to study the module already had a high level of engagement with Twitter, with mobile devices the most popular means of students accessing news content and Twitter the most popular social media platform for such activity. A total of 93 tweets were made using the module-specific \#MD4101 hashtag, with the majority (68) coming from students themselves rather than the module tutor. As discussed in the Introduction, this suggests that social media does indeed foster what Williams, Brown and Benson call a more "egalitarian nature of interaction" (2013: 20) between lecturer and student, with a significant number of students embracing the platform as a means of module communication. Examining the content of the students' tweets suggests that students used Twitter to engage with the topics covered in the module with some sophistication and in some surprising ways. For example, one student used Twitter to conduct her own piece of miniresearch following on from a topic debated in class. Highly relevant content for the module was shared by students, and students' personal positions on issues were conveyed and explored. Students also used Twitter synchronously during classes while face-to-face debates were taking place, thereby blurring the boundaries of digital and non-digital pedagogical reality in accordance with the theory of augmented reality teaching expounded above.

In addition, content posted by students using the hashtag was in some cases then incorporated into subsequent teaching sessions by the module tutor. For me as module tutor, the experience of using a module-specific hashtag on Twitter enabled me to modify future sessions in light of ideas and content posted by students; thus, content that appeared in the later stages of the module was to some extent guided by students' earlier activities using the module hashtag. This was both energizing as a tutor and engendered a sense of a collaborative endeavour. As tutor, it also became apparent that some students who were usually quiet in class were more 
forthcoming and vocal on Twitter, echoing Jimerson's (2015) experience of a Twitter hashtag being a means by which more timid students could be encouraged to participate in module debate. However, some students who were prominent in face-to-face discussions at lectures and seminars also actively used the module hashtag, so Twitter wasn't solely used by introverted students seeking a less intimidating forum to debate course content.

\section{Start-of-Module Questionnaire}

The questionnaire had several key findings in relation to the issue of how relevant it is to integrate a social media platform into the teaching of journalism students. The survey found there was a universal use of social media by the respondents to obtain news, and Twitter was - by a significant margin - the most popular social platform through which journalism students accessed news content, with Facebook second. The survey found that $83.3 \%$ (35) of respondents said a mobile device was their most common means of getting the news, with television second with $14.3 \%$ (six). Every participant $(100 \%, 42)$ answered 'yes' to the question 'Do you use social media to get the news?', confirming the ubiquitous nature of social media-driven online news consumption among journalism students.

Participants were asked to list all the social media platforms they used to get the news. Twitter was listed by $95.2 \%$ (40) of students, Facebook by $78.6 \%$ (33), Instagram by $23.8 \%$ (10) and Snapchat by $16.7 \%$ (seven). Reddit, YouTube and Flipboard were all listed by one student (2.4\%). Twitter's dominance as the most popular social media platform for accessing news was reinforced by the students' responses to the question 'Which social platform do you use most frequently to get the news?' Twitter was named by $76.2 \%$ (32) of participants, with Facebook a distant second with $16.7 \%$ (seven). The answers of the remaining participants ( $7.1 \%$, three) could not be counted because they either listed more than one platform or named a non-social media app (e.g. BBC News).

\section{Analysis of Tweets Using Module Hashtag}

Twenty-seven students actively produced content using the module hashtag, producing 68 tweets in total. The module tutor tweeted 20 times, with a further five tweets being posted by other tutors not teaching on the module. This gave a total of 93 tweets using the module hashtag. Of the tutor's 20 tweets, nine were replies to students' tweets and one was a retweet (the sharing to one's Twitter followers of somebody else's tweet). The tutor's tweets received 31 'likes' and 17 retweets. The tutor's tweets can be broken down into three sub-groups: A, B 
and C. Group A consists of those tweets that encouraged students to contribute using the hashtag or were an acknowledgment/comment on a student's contribution. There were 12 such tweets. Group B consists of those tweets that were the sharing of a webpage ahead of a seminar or lecture, or of content relevant to the module's assessment. There were seven such tweets. Group C comprises the result of a poll of students' opinions about a journalism studies debate that had been held in class. There was one tweet in this group. Examples of A and B will now be presented. Acknowledging students' contributions via Twitter was important to ensure they did not feel like they were talking into a void. As such, as module tutor I would 'like' students contributions or reply to them. One such example of a Group A tweet is:

Sports Journalism@BASportsJourno-23 Oct 2015“@x Thanks for the fab input into \#MD4101 seminar on Facebook's Newsfeed algorithm - and for conducting your own research too!"

The tweet was intended to both acknowledge the student's effort and reinforce the topic that had just been debated. Another example of a Group A tweet was this response to a student's example of how two different outlets could cover the same 'facts' in very different ways:

Sports Journalism@BASportsJourno-7 Nov 2015 “I love this@x and might just have to 'borrow' it for future classes! \#MD4101"

This tweet was intended to foster a sense of collaboration between the student and me, and was indeed used by me in a future class to illustrate a point about how different media organisations can add layers of interpretation or 'spin' to facts.

Group B tweets from the module tutor were those tweets that shared relevant links and materials ahead of pending classes. These were usually in the form of a link to a URL accompanied by either a question or a summary of the article that was intended to draw in students. Two examples are the following:

Sports Journalism @BASportsJourno - 1 Oct 2015 “Check out these front pages: www.bbc.co.uk/news/blogs-the-papers-34408817 Why have different papers selected different stories for their front page? \#MD4101" 
Sports Journalism @BASportsJourno - 8 Dec 2015 “HuffPo’s new chief on the 'post social' mobile era | Media | The Guardian \#MD4101 \#digitalrevolution http://www.theguardian.com/media/2015/dec/06/huffpo-jared-grusd--facebookhuffington"

While the module tutor's tweets arguably set the tone for Twitter communication during the module, it was the students' tweets that were key to assessing engagement. Of the students' 68 tweets using the module-specific hashtag, four were retweets. The students' tweets received 41 likes and five retweets. In no instance was the hashtag misused by a student to post irrelevant or inappropriate content. An important caveat is that in some instances students engaged with the module on Twitter but without using the module hashtag. These instances have been excluded from the data because of the difficulty in being certain that all such tweets have been captured. As with the analysis of the module tutor's tweets, the students' tweets can be broken down into sub-groups (A-G). The sub-grouping of tweets is summarised below, along with the number of tweets that fall into each category:
A tweets made during class responding to material that had been delivered: 16
B sharing articles/clips that are relevant to the module: 25
C commenting on media issues/media decisions: 22
D research: one
E sharing details of their own media consumption activities: two
F commenting on their assessment: one
$\mathrm{G}$ replying to lecturer's reply: one

The variety of posts was one of the most interesting and, from my position as the module tutor, one of the most rewarding aspects of the use of the module-specific hashtag. A post by one journalism student consisted simply of a cartoon about Facebook's power unaccompanied by nothing other than the hashtag - a post seemingly designed to provoke a thoughtful response among classmates; another post using the hashtag was made almost a month after the submission date for the module's assessment and was done to share the breaking news about the London-based newspaper The Independent becoming a digital-only publication. The fact that a student opted to use the module hashtag four weeks after the module had ended 
was a strong indicator that the use of the hashtag had succeeded in engaging the students about journalism studies. Another rewarding aspect of students' use of the module hashtag was to see them wrestling with an issue as they tried to come to a conclusion, as one student did through two tweets about the future of the BBC license fee.

During one session at the beginning of the course, I asked the students to take part in a 'counter-factual' thought experiment and consider what would have happened if major events in world history had been able to be reported using social media. In another session, I asked them to consider whether the omnipresence of 24/7 news was good or bad for democratic society. These in-class debates prompted simultaneous input on Twitter (Group A tweets), with students contributing both face-to-face and in real-time on Twitter using the hashtag. This was an example of the "enmeshing of the on and offline" (Jurgenson 2012: 2) and an illustration of what I have termed augmented reality teaching, which involves the blurring of the distinction between online and offline teaching. On 30 September 2015, for example, one student posted "Some interesting ideas about what would happen if JFK's death was reported in the $21^{\text {st }}$ century... \#MD4101" while on 21 October 2015 another tweeted: "I'm torn - it's positive in that we're better informed as a society, but negative as we're desensitized to the news \#MD4101".

One example of a Group B tweet was the sharing on 16 November 2015 of a BBC radio show in which the student also helpfully provided the timings of the relevant audio: "Henry Winter on how the digital revolution piles more pressure on managers 53:14-54:45 @BASportsJourno \#md4101". Such content was useful not only for fellow students but for me as module tutor, as it alerted me to potential debating points for future seminars and lectures. The successful engagement of students through the use of the module-specific hashtag was also indicated by tweets such as one on 19 November 2015 in which a student provided a link to an article in The Independent about a terrorist attack in Paris and said: "Following on from Wednesday, this really struck me \#md4101".

Students were also prepared to voice their own views on important journalism studies topics by using the module hashtag. On 7 October 2015, for example, one student commented on the issue of news values and story selection, which had just been covered in class, by saying "Think England out of the (rugby) world cup being before a young boy died (sic) in bus crash shows maybe news lists on BBC should be changed \#md4101". And on 1 November 2015, 
another commented on the debate about the BBC licence fee by tweeting "Agree with Greg Dyke, BBC has invented British television and it would be bad for the country if it didn't exist in any form \#md4101". The voicing of such out-of-class opinions using the module hashtag was another indicator of the hashtag being a powerful way of engaging the students. Another indication that the use of Twitter helped foster student engagement came through a student's decision to use the hashtag to share a mini 'experiment' she had done. Following a seminar in which the mechanics and ethics of Facebook's newsfeed algorithm were discussed, the student conducted her own rough experiment to see whether the use of certain words in a Facebook status update lifted her update to the top of friends' newsfeeds. Her findings were shared with classmates on Twitter when she tweeted on 21 October 2015 "\#md4101 so I do an experiment and apparently I'm on the top of 34 peoples (sic) Facebook news feeds! Interesting!" The hashtag was used in other diverse ways, too, with students occasionally using it to share with their classmates the media they were reading or listening to, as when one student posted a photo of the front page of the London Evening Standard on 29 October 2015 accompanied by the words “\#md4101 on the tube so why not!!" Although a perhaps trivial post which little bearing on module content, it nevertheless served to suggest that the student was engaged with the module and thinking about it even when off campus, and as module tutor it was vindicating to witness this.

\section{Limitations}

The case study was of a small sample of journalism students at a single university. To broaden its scope, future studies could be done with a larger sample of journalism students across a number of institutions, or with students from a wider pool of subjects at the same university (for example, media courses more generally). A post-module focus group that gathered qualitative data on students' experience of the module hashtag might have added greater richness to the findings, and a future study could focus on the assessment performance of those journalism students who engage with the use of the hashtag compared with the performance of those who do not. As previously mentioned, another limitation of the study is that a number of module-related tweets did not use hashtags and were therefore 'lost' and not accounted for in the data.

\section{Conclusion}


This case study of first-year journalism students' engagement with a module-specific hashtag has shown that the students' use of the hashtag was varied, creative, always 'on topic', and both synchronous and asynchronous with face-to-face teaching. It also revealed the central role of Twitter in journalism students' news consumption. Content analysis of the tweets posted by students suggested that Twitter facilitated considerable levels of engagement with the module across both time and space; students contributed both during classes and in one case long after the module had officially ended, and they also contributed through Twitter when geographically highly remote from the physical classroom. From the module tutor's autoethnographic perspective, the use of the hashtag enriched the teaching of the module by enabling students to contribute content that could be incorporated into subsequent teaching sessions. The use of the hashtag also facilitated the kind of "enmeshing" of the digital and non-digital spaces that Chayko (2017) and Jurgenson (2012) describe. Brenton (2015) contends that e-learning is unlikely to work when it is somehow bolted-on to the core part of the module. The teaching strategy deployed in this module was intended to avoid this 'bolting-on' phenomenon and instead integrate the use of the Twitter hashtag into the heart of the module, thereby cohering with the theories of augmented reality teaching and pedagogyindustry alignment. 


\section{References}

Allen-Collinson, J. (2012) 'Autoethnography: Situating Personal Sporting Narratives in Socio-Cultural Contexts' in Qualitative Research on Sport and Physical Culture (ed. Young, K. \& Atkinson, M.) pp.191-212. Bingley: Emerald.

Brenton, S. 'Effective online teaching and learning' in Fry, H., Ketteridge, S \& Marshall, S. (eds.) (2015) A Handbook for Teaching and Learning in Higher Education: enhancing academic practice, 4th ed. Oxford: Routledge

Chayko, M. (2017) Superconnected: The Internet, Digital Media, and Techno-Social Life. London: Sage

Cochrane, T. (2014) 'To lecture or not to lecture: is technology reinventing the campus?' https://theconversation.com/to-lecture-or-not-to-lecture-is-technology-reinventing-thecampus-21328 (Last accessed: November 20, 2015)

Cormier, D. (2014) Community learning - the zombie resurrection taken from Dave's Educational Blog - Education, post-structuralism and the rise of the machines. http://davecormier.com/edblog/2014/05/25/community-learning-the-zombieresurrection/ (Last accessed: May 18, 2016)

Dawson, P. (2014) ‘Are lectures a good way to learn?' http://theconversation.com/arelectures-a-good-way-to-learn-26905 (Last accessed: 19 May 2016)

Ellis, C. \& Adams, T.E. (2014) 'The Purposes, Practices, and Principles of Autoethnographic Research' in The Oxford Handbook of Qualitative Research (ed. P. Leavy), pp.254276. Oxford: OUP

Ingram, M. (2015) 'The attention economy and the implosion of traditional media'. http://fortune.com/2015/08/12/attention-economy/. (Last accessed: May 19, 2016)

Jimerson, L. (2015) 'How an art history class became more engaging with Twitter'. http://theconversation.com/how-an-art-history-class-became-more-engaging-withtwitter-47133. (Last accessed: 1 April, 2016)

Junco, R., Elavsky, C.M. \& Heiberger, G. (2013) 'Putting twitter to the test: Assessing outcomes or student collaboration, engagement and success' in British Journal of Educational Technology Vol.44 No.2, 2013, pp.273-287

Junco, R., Heiberger, G. \& Loken, E. (2011) 'The effect of Twitter on college student engagement and grades' in Journal of Computer Assisted Learning. 27, 2, pp.119-132 
Jurgenson, N. (2012) 'When Atoms Meet Bits: Social Media, the Mobile Web and Augmented Revolution' in Future Internet 2012, 4, pp.83-91. Retrieved from: http://www.mdpi.com/1999-5903/4/1/83

Marwick, A. E. (2015) 'Instafame: Luxury Selfies in the Attention Economy' in Public Culture Jan 2015, Vol. 27 Issue 1, pp.137-160

Melville, D. (2009) Higher education in a Web 2.0 world. JISC Report. Available at: http://www.jisc.ac.uk/media/documents/publications/heweb20rptv1.pdf (Last accessed: 20 May 2016)

O’Reilly, K. (2012) Ethnographic Methods. Abingdon: Routledge

Williams, B. Brown, T. \& Benson, R. (2013) 'Feedback in the digital environment' in Boud, D. and Molloy, E. (eds.) Feedback in Higher and Professional Education: understanding it and doing it well. Abingdon: Routledge 